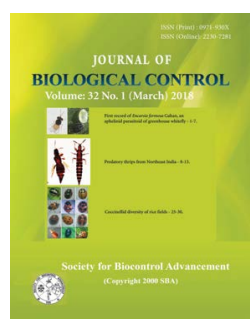

\title{
Seasonal population dynamics of spider mite, Tetranychus ludeni Zacher (Tetranychidae) and associated predatory mite, Neoseiulus sp. nr. neoghanii (Phytoseiidae) on tomato (Solanum lycopersicum L. var. Solan gola: Solanaceae) from Himachal Pradesh, India
}

\author{
VIJAY SINGH ${ }^{*}$ and USHA CHAUHAN \\ Department of Entomology, Dr YSP University of Horticulture and Forestry, Nauni, Solan - 173230 , \\ Himachal Pradesh, India \\ *Corresponding author E-mail: vijay4chandel@gmail.com
}

\begin{abstract}
The study was carried out during 2013 and 2014 on tomato (var. Solan gola) in open field. Infestation of Tetranychus ludeni Zacher was recorded. Predatory mite viz. Neoseiulus sp. nr. neoghanii was observed in association with T. ludeni. Maximum population of T. ludeni was recorded during June month both years with population $2.6 \pm 0.58$ (2013) \& $2.3 \pm 0.42$ (2014) mites/leaf. N. sp. nr. neoghanii was observed in June and July month. Population was $0.2 \pm 0.2$ mites/leaf both years. Populations of T. ludeni and N. sp. nr. neoghanii showed a positive correlation with average temperature and negatively correlated with relative humidity. Occurrence of these species on this crop was the first report from this region. The study will be useful in bio control programme in near future.
\end{abstract}

KEY WORDS: Biological control, mite, phytophagous, predator

(Article chronicle: Received: 02-06-2017; Revised: 06-02-2018; Accepted: 12-03-2018)

\section{INTRODUCTION}

Tomato (Solanum lycopersicum L.) is an important vegetable of Himachal Pradesh and plays an important role in uplifting the economy of farmers in the state. This crop is grown on a commercial scale in the mid hill regions under protected as well as in open field. This vegetable is attacked by a number of pest species. Worldwide, more than one hundred pests have been reported on this crop (Taleker et al., 1983). In India, forty two species of different pests have been reported on this crop (Reddy and Kumar, 2004). Eight pest species were also reported on tomato and other vegetables from Himachal Pradesh (Vashisth et al., 2013). Pests not only causes major losses to the quality and quantity but act as vector of various diseases. (Dharumarajan et al., 2009). Yield loss in vegetables was approximately 9.15$100 \%$ or some time failure of the crop due to pests attack (Gupta, 1991; Prasad and Singh, 2007; Prasad et al., 2007; Patil and Nandihalki, 2009; Vinothkumar et al., 2009).

Mites belonged to the family Tetranychidae and Eriophyidae are among the destructive pests on various crops in many parts of the world (Pokle and Shukla, 2015a). The two spotted spider mite is cosmopolitan in its distribution and reported as one of the serious pest on various crops (Manjulata et al., 2002). Introduction of high yielding varieties, improvements in cultural practices and indiscriminate use of pesticides since last three decades have made these pests become more serious (Prasad et al., 2007). Due to their short life cycle, they are reported to develop resistance against different chemicals (Kumar et al., 2002; Sridhar and Jhansi Rani, 2003; 2007).

So, the need of need of the hour is to apply IPM practices to overcome the problem of resistance and to check the economic loss of farmers. Biological control offers an efficient alternative to check their population below economic injury level (Mahr et al., 2008). Predatory mites are reported as potential predators of spider mites throughout the world (Rachana et al., 2009; Bjorson, 2008; Zhang, 2002). But, before using these natural enemies as biological control agents, it is essential to know about their habitat and seasonal population. So, keeping this in view, the present investigation was carried out to know the seasonal incidence of spider mite and predatory mites association on tomato. 


\section{MATERIALS AND METHODS}

Study was carried out during 2013 and 2014 on tomato crop (var. Solan gola) in open field at experimental farm, Department of Entomology. Seedlings were planted in the month of April for both the years and data was recorded from May to August at fifteen days interval. For data observation five plants were selected randomly. Samples of fifteen leaves from each plant were plucked and placed in polythene bag tied with rubber band. Samples were kept in refrigerator at $5^{\circ} \mathrm{C}$ overnight to immobilize the mites. Samples were observed under stereo zoom microscope (Olympus SZX 9) and only motile stages were counted carefully. Mean population and standard error of mean was calculated through one way ANNOVA.

Correlation between population dynamics and abiotic factors (i.e. average temperature and relative humidity) were carried out and correlation coefficient was calculated.

\section{Identification}

For identification, the mite specimens were mounted in a drop of Hoyer's medium on microscopic slides (Singh and Raghuraman, 2011; Jeppson et al., 1975). Slides were dried in hot air oven at $35-40^{\circ} \mathrm{C}$ for $4-5$ days. Specimens were observed under phase contrast microscope (Olympus SZX 41) and identification was done by following standard keys (Gupta and Gupta, 1994; Gupta, 2002, 2003; Chant and McMurtry, 2007).

\section{RESULTS AND DISCUSSION}

Infestation of Tetranychus ludeni Zacher was observed throughout the crop season. Only phytoseiid i.e. Neoseiulus sp. nr. neoghanii was recorded in association with the population of T. ludeni. Data were recorded for two crop seasons during 2013 and 2014.

Seasonal population of Tetranychus Iudeni and Neoseiulus sp. nr. neoghanii during 2013 and 2014

Average population of T. ludeni was $1.2 \pm 0.42$ mites/ leaf (2013) and $2 \pm 0.42$ mites/leaf (2014). Increase in population was recorded in the month of June for both the years i.e. $2.6 \pm 0.58 \mathrm{mites} / \mathrm{leaf}$ in 2013 and $2.3 \pm 0.42 \mathrm{mites} / \mathrm{leaf}$ during 2014. Population decline was also recorded from July to August during the years. Population of T. ludeni during these months were $2.1 \pm 0.43 \& 1 \pm 0.42$ mite/leaf (2013) and $2.2 \pm 0.43 \& 1.2 \pm 0.41$ mite/leaf during 2014 (Figure. 1).

Neoseiulus sp. nr. neoghanii was observed in association with T. ludeni during June and July months of 2013 and 2014. Average population was $0.2 \pm 0.2 \mathrm{mites} / \mathrm{leaf}$ respectively (Figure 1).

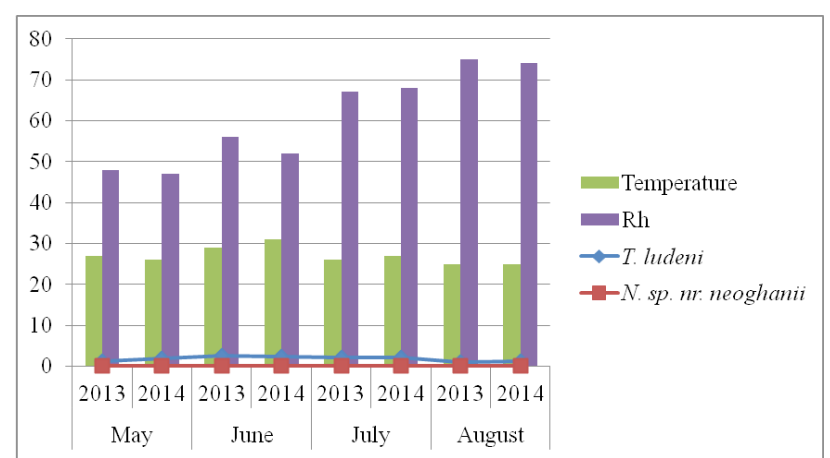

Fig. 1. Seasonal population dynamics of Tetranychus and Neoseiulus sp. nr. neoghanii on tomato (var. Solan gola) during 2013 and 2014.

The correlation study of mite population with abiotic factors viz. average temperature and relative humidity were also worked out (Table 1). The population of T. ludeni showed a high positive correlation with temperature during the period of study however population was negatively correlated with relative humidity (Table 1). Population of $N$. sp. nr. neoghanii was positively correlated with temperature for both the years but showed no correlation with relative humidity during 2013 but negatively correlated with relative humidity was observed 2014 (Table 1).

Table 1. Correlation between population of Tetranychus Iudeni Zacher and Neoseiulus sp. nr. neoghanii with abiotic factors on tomato (var. Solan gola) during 2013 and 2014

\begin{tabular}{|l|l|l|l|l|}
\hline Climatic Factors & \multicolumn{2}{|l|}{ T. ludeni } & \multicolumn{2}{l|}{$\begin{array}{l}\text { Neoseiulus sp. nr. } \\
\text { neoghanii }\end{array}$} \\
\hline & 2013 & 2014 & 2013 & 2014 \\
\hline Temperature $\left({ }^{\circ} \mathrm{C}\right)$ & 0.731 & 0.730 & 0.507 & 0.768 \\
\hline Relative Humidity $(\%)$ & -0.202 & -0.621 & 0 & 0.022 \\
\hline
\end{tabular}

Earlier, infestation of T. ludeni was reported by Sood and Kakar (1990) on Dahlia sp. from Himachal Pradesh. Rachana et al. (2009) reported two species of phytoseiid viz. Amblyseius longispinosus (Evans) and Phytoseilus persimilis A\&H on okra in association with T. neocaledonicus. Population of T. neocaledonicus was high in the month of April whereas population of $A$. longispinosus and P. persimilis was reported during July and October. Zhang (2002) and Rachana et al. (2009) reported Phytoseiulus persimilis as natural enemies of spider mites on different vegetables but the T. ludeni population was low Pokle and Shukla (2015a) reported infestation of T. urticae on tomato under polyhouse condition from Navsari, Gujarat. During their study they observed that the maximum population of mites in the month of June and population was positively with correlated with the average temperature and relative humidity. These studies supported the present investigation. Infes- 
tation of A. lycopersici was reported on tomato with population peak during May month (Pokle and Shukla, 2015b). They reported a positive correlation between abiotic factors and mite population. Solangi et al. (2017) reported infestation of Eriophyes sheldoni latus Banks on tomato in Pakistan and highest population increase was observed from May and June. These studies support the present investigation.

This study will be useful in the bio control of phytophagous mites and other soft bodied pests on tomato. So, there is need to conserve and mass multiply these beneficial organisms for use in IPM programs which will reduce the use of synthetic chemicals on various crops and make the environment safe.

\section{ACKNOWLEDGEMENT}

The authors are highly thankful to Head, Department of Entomology for providing the necessary facilities and Dr. S. K. Gupta (Former Joint Director, ZSI, Kolkata) for confirming the identification.

\section{REFERENCES}

Bjorson S. 2008. Natural enemies of mass reared predatory mites (Family: Phytoseiidae) used for biological control. Exp Appl Acarol. 46 (1-4): 299-306. https:// doi.org/10.1007/s10493-008-9187-1 PMid:18726699

Chant DA, McMurtry JA. 2007. Illustrated keys and diagnoses for the genera and subgenera of the Phytoseiidae of the world (Acari: Mesostigmata). Indira Publishing House. 220p. PMCid:PMC1914523

Dharumarajan S, Dikshit AK, Singh SB. 2009. Persistence of Combine-Mix (beta-Cyfluthrin + imidacloprid) on Tomato (Lycopersicon esculentum), Pesticide Res J. 21(1): 83-85.

Gupta SK. 2002. A monograph on plant inhabiting predatory mites of India. Part I: Order: Prostigmata, Astigmata and Cryptostigmata. Memoirs Zool Surv India 19(2):1-185.

Gupta SK. 1991. The mites of agricultural importance in India with remarks on their economic status. In: Dusbabek F, Bukva V (Eds,). Modern Acarology Vol. I, Academia Prague and SPB Academic Publication, The Hague. pp. 509-522.

Gupta SK. 2003. A monograph on plant inhabiting predatory mites of India. Part II: Order: Mesostigmata. Memoirs Zool Surv India 20(1): 1-185.
Gupta SK, Gupta YN. 1994. A taxonomic review of Indian Tetranychidae (Acari: Prostigmata) with description of new species, re-descriptions of known species and key to the genera and species. Memoirs Zool Surv India 18(1): 1-162.

Jeppson LR, Keiffer HH, Baker EW. 1975. Mites injurious to economic plants - Handbook. University of California Press, Berkley, California. PMid:1103278

Kumar S, Prasad S, Singh RN. 2002. Resurgence of two spotted mite, Tetranychus urticae Koch. (Acarina: Tetranycidae) due to acaricides and botanicals on okra. Ann Pl Protec Sci. 10(2): 239-242.

Mahr DL, Whitaker P, Ridgway N. 2008. Biological control of insects and mites: An Introduction to beneficial natural enemies and their use in pest management. Extension biological control programs, Department of Entomology, University of Wisconsin-Madison .120 pp.

Manjulata K, Shashi B, Varma BR, Kapur M, Bhalla S. 2002. Pest risk involved in import of roses and its germplasm. Ind J Ent. 64(4): 465-470.

Patil RS, Nandihalli BS. 2009. Efficacy of promising botanicals against red spider mite on brinjal. Karnataka $J$ Agri Sci. 22: 690-692.

Pokle PP, Shukla A. 2015a. Population dynamics of russet mite, Aceria lycopersici (Acari: Eriophyidae) on tomato under polyhouse conditions. J Exp Zool India 18(2): 737-740.

Pokle PP, Shukla A. 2015b. Population dynamics of two spotted spider mite, Tetranychus urticae (Koch) (Acari: Tetranychidae) on tomato under polyhouse condition. J Appl Biosci. 40(2): 148-151.

Prasad R, Prasad UK, Sathi SK, Prasad D. 2007. Mite pest scenario and their status associated with common vegetables. Indian J Curr Sci. 10(1): 269-274.

Prasad R, Singh J. 2007. Estimation of yield loss in okra caused by red spider mite (Tetranychus urticae Koch) under the influence of two dates of sowing. J Entmol. 69 (2): 127-132.

Rachana RR, Manjunath M, Devi G, Naik MI. 2009. Seasonal incidence of red spider mite Tetranychus neocaledonicus Andre and its natural enemies. Karnataka J Agric Sci. 21(1): 213-214. 
Reddy NA, Kumar CTA. 2004. Insect pests of tomato, Lycopersicon esculentum Mill. in eastern dry zone of Karnataka. Insect Environ, 10(1): 40-42.

Singh J, Raghuraman M. 2011. Emerging scenario of mite pests in India. Zoosymposia 6: 172-179.

Sridhar V, Jhansi RB. 2003. Relative susceptibility in open and greenhouse populations of two-spotted spider mite, Tetranychus urticae Koch on Rose to Dicofol. Res Pest Mgmt Newsletter 12: 83.

Sridhar V, Jhansi RB. 2007. Resistance in two-spotted spider mite, Tetranychus urticae Koch on rose from different polyhouses to dicofol and wettable sulphur. $J$ Acarol. 17: 48-50.

Talekar NS, Ying F, Song T. 1983. Tomato insect pest: major management strategies. In: Proceedings of the Symptomatic Insect Control of Vegetables (Taiwan). pp. 1-19.
Vashisth S, Chandel YS, Kumar S. 2013. Observations on insect-pest problems of polyhouse crops in Himachal Pradesh. J Entomol Res. 37(3): 253-258.

Vinothkumar S, Chinniah C, Muthiah C, Sadasakthi A. 2009. Field evaluation of acaricides/insecticide molecules for their bio-efficacy against Tetranuchus urticae Koch on brinjal. Karnataka J Agric Sci. 22: 706-706.

Sood AK, Kakar KL. 1990. Record of non-insect pests of ornamental plants from Himachal Pradesh. J Insect Sci. 3(2): 141-45.

Solangi BK, Khoso FN, Shafique MA, Ahmed AM, Gilal AA, Talpur AMA, Dhiloo KH. 2017. Host plant preference of sucking pest complex to different tomato genotypes. J Entomol Zool Stud. 5(1): 293-297.

Zang ZQ. 2002. Taxonomy of Tetranychus ludeni (Acari: Tetranychidae) in New Zealand and its ecology on Sechium edule. New Zealand Entomologist 25(1): 27-34. 